\title{
Analyzing Barriers in e-Government Implementation in Pakistan
}

\author{
Muhammad Bilal Kayani \\ University of Bolton \\ Bolton, United Kingdom
}

\author{
M. Ehsan ul Haq, M. Raza Perwez, Hasan Humayun \\ National University of Modern Languages, \\ Islamabad, Pakistan
}

\begin{abstract}
This paper presents the e-Government capabilities and thereby identifies barriers within $e$ Government implementation in Pakistan. The eGovernment is the use of technology by government for its citizens so as to provide faster and better access to e-services to Pakistani citizens. There is a lot of interaction which takes place between government and citizens in modern world. The eGovernment is an initiative, presented by the government so that it can offer easy and fast services to its citizens online. Other than citizens, businesses and employees are also the key beneficiary of a wellplanned e-Government framework. However the paper looks into the various obstacles faced by Pakistan for implementation of the e-Government services. This study focused on literature, different multi stages models for implementation of the $e$ Government and various e-readiness models. A proposed model based on questionnaire which distributed among the citizens and government employees, who are familiar with the e-Government and information technology. The research also presents the analysis of various obstacles such as information technology infrastructure, lack of information technology skills, legal obstacles, security issues and the way citizens are using eservices in Pakistan.
\end{abstract}

\section{Introduction}

In the last decade or so, a revolution has been witnessed all over the world with respect to transformation in the information and communication technologies (ICTs). This is not only changing the way business is being done all over the world but has also transformed the lives of people. Citizens all over the world have now been moving closer to the government due to the revolution of information and communication technologies. This interaction between the government and its citizens has led to closer ties between both the parties which have further led to introduction of a robust network known as e-Government [1].

The e-Government is basically the use of technology by the government for its citizens by which government can provide easier and faster access to lot of services. Other than citizens, businesses and employees are also the key beneficiary of e-Government. Its main benefits are the reduction of error rate, reduction in paper wastage, faster work leading to faster decision making and greater convenience. The e-Government is a way in which governance of the government has been often linked. The e-Government also helps the government to make better and stronger relations. It offers a host of services ranging from online tax payment, license renewal, motor registration, payment of fines, and submission of documents [2].

The key to a successful e-Government plan is about the use of technology but still in many countries the internet usage is in the infant stage and that is why developing countries are facing hurdles to implement the e-Government [1]. There are so many benefits which the e-Government can bring to both the government and the citizens as a whole including businesses, employees and other agencies. There is a considerable amount of savings in both time and time and access is possible 24 hours a day and seven days a week round the clock. The eGovernment benefits sounds very attractive but it is not possible without having obstacles. Addressing obstacles in the e-Government is a challenge especially for developing economies [3].

Governments across continents and countries are embracing a government system which is electronic in nature. Every county whether developed or developing, rich or poor are using electronic system as a means to flow information which is very critical and beneficial for its stakeholders at large. The major factor which drives the government's initiative in adopting e-Government practice is because of the motivation to improve the negative image of government [4]. Citizens often blame the government for either being too slow, unproductive, or unresponsive for most of present day needs. Government thereby wants to embrace technology and disseminate information in the smoothest way to the public at large. It is basically the use of ICT so as to have an effective and efficient mechanism for flowing information whereby government and its agencies can become directly accountable to its own citizens.

The e-Government puts pressure on the government in form of many resources being committed and its failure can cost a lot of financial and political risk. Moreover this government might have lot of technological and other infrastructure constrains in adopting e-Government. Weak education system and unequal access to technological system is also deterrent to the use of e- 
Government. The success of e-Government depends much on how the government works and how changes take place within the government machinery so as to flow the information to the citizens. Creating a better image by the government is very important in entire e-Government process. The e-Government is more about transforming government so that it can become more citizen-centric.

Information technology is playing a very important role in the life of people all over the world and it changing the life of people and changing the rules of doing business. E-Government has been one such area whereby government is using Information and communication technologies (ICTs) to provide speedy and efficient services to people at large.

Although the aim of e-Government is for enriching the lives of citizens, business, employees and other agencies the journey is not smooth and without obstacles. Obstacles like citizen awareness about e-services, and shortage of skilled and technical workers in this direction poses major obstacles towards e-Government in developing economies. Also the complexity in e-Government program is very wide and this poses major challenges before the government machinery to implement on a larger scale. Governments across the world are embracing electronic government. There has been critical pressure on developing economies for disseminating important information to the public at large. Pakistan is also a developing nation and is embracing e-Government in its system.

However there are so many hurdles in the eGovernment implementation across the country. The researcher wants to study the problem of obstacles occurring in establishing the e-Government in Pakistan and to recommend steps to ensure that there is a better environment in which implementation of the e-Government can be done. This study focuses on assessing the capabilities and identifying the obstacles in implementation of the e-Government in Pakistan.

Rest of the paper is organized as follows: Section II presents Literature Review which highlights literature available on the topic alongwith models which give the reader an overall view of the research undertaken. Section III is based on Research Methodology which focuses on methods and techniques so employed in the research alongwith justification for the same. Section IV presents the data collection and analysis which presents the results and its inference drawn from the research. Conclusion and recommendations are presented in section $\mathrm{V}$.

\section{Literature Review}

Governments across continents and countries are embracing a government system which is electronic in nature. Every country whether developed or developing, rich or poor are using electronic system as a means to flow information which is very critical and beneficial for its stakeholders at large. The major factor which drives the government's initiative in adopting e-Government practice is because of the motivation to improve the negative image of government [4]. Citizens often blame the government for either being too slow, unproductive, or unresponsive for most of present day needs. Government thereby wants to embrace technology and disseminate information in the smoothest way to the public at large. It is basically the use of ICT so as to have an effective and efficient mechanism for flowing information whereby government and its agencies can become directly accountable to its own citizens.

The e-Government which is also better known as electronic government is a way of disseminating information to the general public about the services which are available and offered by government and their respective agencies. The information can be related to payment of tax, receipt of various benefits, and availability of passport. The e-Government may flow the information via telephone, internet and other help kiosks i.e. self service centre or any other wireless systems [5].

Government is a larger institution and governance is a broader topic in itself. Corporate governance may refer to the way in which the private sector places its internal mechanism and controls so as to keep the stakeholders accountable while government here will only be a part of it through company law. Governments contribute to good governance [6]. The e-governance is electronic governance which is transformed in the modern times of information age where an information and communication technology (ICT) ensures superior level of governance [7].

"e-Government is a set of processes and structures which are prevalent for the e-delivery of services to the citizens at large" [8]. E-Government is more about improving efficiency and effectiveness of the government by ICT to citizens. The eGovernment is a means of providing and transferring services to the public via the internet about its various departments, agencies and services about its transactions [9].

The Government is supremacy where transition happens to the society from politics to policies and into legislation. On the other hand governance is the derivative of the interface between the government, citizens and the public service in the entire process and service delivery. Government is the way which can contribute to the governance. Governance happens through politics, procedures, policies and programs.

The e-Government services can be classified into four main areas i.e. to citizens, to business houses, government employees and government departments or agencies. The main aim and goal of 
e-Government is to have a long term relation with the citizens, businesses, employees and agencies so as to offer them convenience and effective services. Overall the e-Government service it from G2C (Government to Citizen), G2B (Government to Business), G2E (Government to Employee) and Government to Government (G2G).

\section{Research methodology}

This study is mainly descriptive, aiming to find out and describe the effective factors, which influence the implementation of the e-Government in Pakistan. It also provides basic understanding of the effective factors in implementation of the egovernment with a new model. Descriptive research studies is used which help to find out factors that influence the broader implementation of eGovernment program in Pakistan. The research is performed by surveying certain people about their experiences and requirements about e-government services and discussed obstacles with government employees. Since the main aim of this research is to apprehend the barriers which are present in implementing the e-Government program in Pakistan, quantitative research is the most appropriate tool used for the purpose.

Data has been collected with the help of a survey by using questionnaire and interviewed. Items in the questionnaire measured current e-services using by citizens and important obstacles of implementing e-government in government employees and followed some case studies to find out how other countries implemented e-government in their own countries. Non-probability sampling and judgmental non probability based sampling techniques are used for this research study. A sample is selected from the list to be provided by the government machinery and citizens of Pakistan.

Two questionnaires were prepared, one questionnaire for the citizens about the e-services and their experiences and the other for the government departments to discuss the e-government obstacles. A set of 230 questionnaires circulated in the citizens and government departments of Pakistan. This generated a large number of responses as the population under researcher was quite large itself. It is observed that there were better responses from government employees, officers and citizens in case of personal interviews than questionnaires.

Primary data was collected with the help of 200 questionnaires, which is used to collect data from 100 respondents who are associated with the government machinery of Pakistan and 100 respondents from the citizens of Pakistan.

A self-administered questionnaire formed since the research might be done through e-mail, telephone or direct mail. The questionnaire was designed based on the E-readiness model of the government which is stated in the Literature Review. The questionnaire from citizens was based on e-services, their experience, barriers and how they use e-Government services. The questionnaires from government machinery about the barriers are divided into five categories ranked as 1 to 5 . Barriers are as under: -

- Infrastructure barriers

- Regulatory barriers

- $\quad$ Skilled personnel barriers

- $\quad$ Security barriers and

- Social and cultural barriers

\section{Data Collection and Analysis}

The research is done primarily to identify the barriers in implementing e-services in Pakistan. Pakistan is a developing nation and its development largely depends on the development of its citizens as well. Providing e-services to citizens would ensure that timely and correct e-service is provided by the government.

\subsection{Survey Findings}

Pakistan is an area of more than 790,000 square kilometer. According to the UNICEF statistics the literacy rate in Pakistan is about 58 per cent. The following graph presents the result of the findings of the research so conducted.

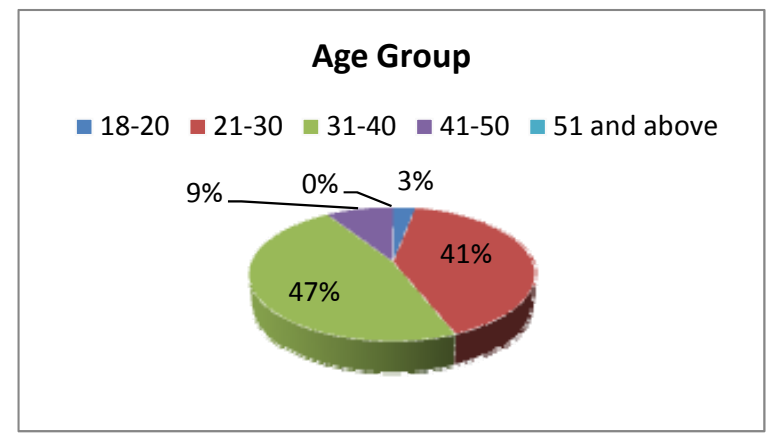

Figure 1. Age Group

A total of 100 citizens of Pakistan were interviewed for this purpose. Overall the age group of the citizens lied between the ages of 21-40 years. Maximum forty seven per cent of the people were in the age bracket of 31 and 40. There were no respondent over the age group of 51 years and very few respondents were available for comments in the age bracket of 18 and 20 as well as 41 and 50 .

Internet as a medium of communication and knowledge has been widely used by a large number 
of citizens in Pakistan on a frequent basis. Out of the total set of respondents, around 83 per cent used Internet on daily basis. Weekly use of internet was pointed out by 15 per cent of the respondents. Only 02 percent of the respondents used internet on a monthly basis with none of the respondents citing the use of internet once in a year basis.

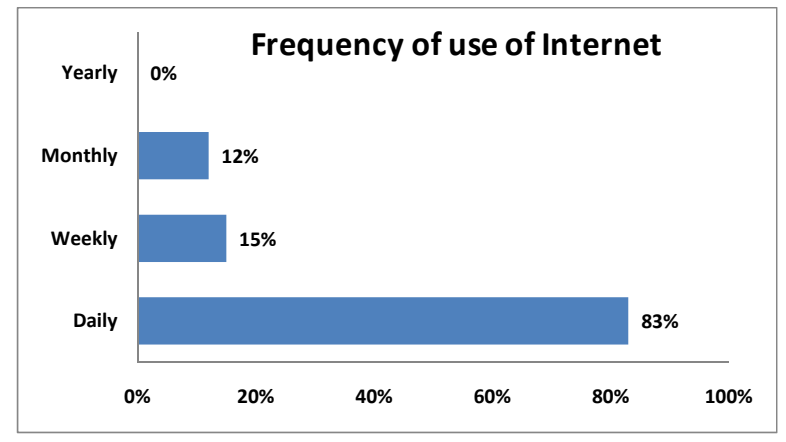

Figure 2. Frequency of use of Internet

Out of the total respondents interviewed for the research a whopping 73 per cent of them stated that there are so many barriers in the e-Government services of Pakistan. Only 27 per cent stated that there are no barriers in the e-Government of Pakistan. Out of the total respondents only 02 per cent of the respondents were using e-services regularly on a weekly basis. None of the respondent was using it on a daily basis. A majority, the 74 per cent respondents were using the e-Government services whenever they needed it. The 03 percent of the population has never used e-Government services in their life.

The 89 per cent respondents are expecting new and better e-services to be introduced by the government of Pakistan. Only 11 per cent respondents are happy with current e-Government services offered by the Pakistani government. The 79 per cent respondents are using the e-Government services from their personal computers and only 13 per cent and 08 per cent people are using it from kiosk and company work station.

The 73 per cent respondents stated that there are a lot of barriers in the e-Government services of Pakistan. Only 27 per cent stated that there are no barriers in e-Government of Pakistan. Only 02 per cent respondents were using e-Services regularly on weekly basis. None of the respondent was using it on a daily basis. A majority 74 per cent were using eGovernment services whenever they needed it. The 03 per cent of the population has never used eGovernment services in their life.

The 89 per cent majorities of the respondents are expecting new and better e-services to be introduced by the government of Pakistan. Only 11 per cent of the respondents are happy with the current e-
Government services offered by the Pakistan government.

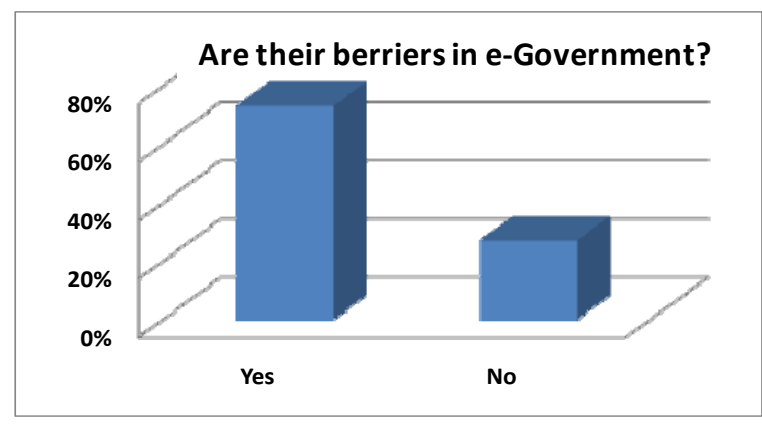

Figure 3. Are their Barriers in e-Government

The 79 per cent of the respondents are using eGovernment services from their personal computer, only 13 per cent are using it from kiosk and 08 per cent are using it from company work station.

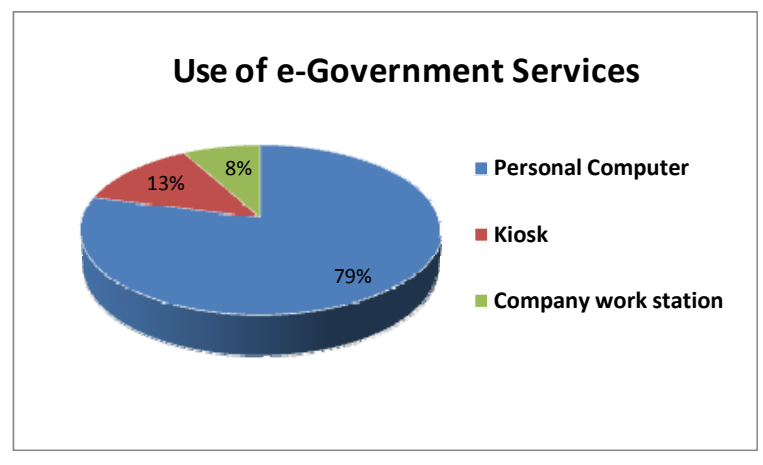

Figure 4. Use of e-Government services

Out of the various e-services offered by the Pakistani government under its e-services initiative a maximum of respondents were using education services, utility bills services, taxation, passport and job related e-services.

While asking questions pertaining to e-service experienced by Pakistani citizens only top five of the services were questioned by the researcher to the respondents. The research data collected for other services had very few responses and for this reason asking the respondent about the response would not bring out any major finding.

A maximum of 08 per cent respondents stated services that taxation services are good and other 07 per cent were of the view of being average. As far as utility services are concerned, 8 per cent respondents stated it being good and 03 per cent stated it to be on an average. With respect to jobs, only 03 respondents stated it as being good and other 05 viewed it as being on average. 


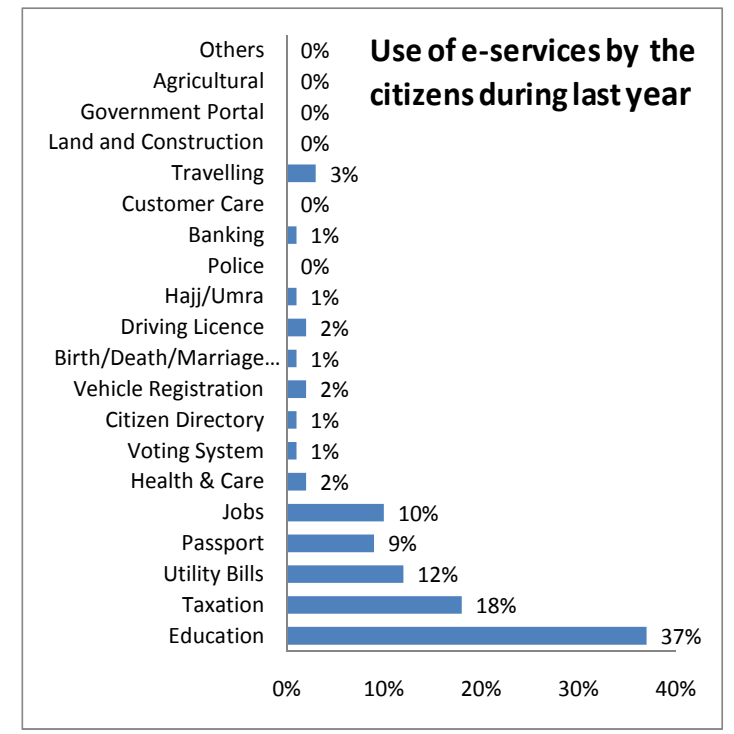

Figure 5. Use of the e-services during the last year

A major point out of this data finding was that no respondent experienced the service as being very good. The analysis here states that citizens somewhere down the line are not completely satisfied by the e-services given by the Pakistani government. There needs to be a lot of improvement required in areas of e-service implementation by Pakistani government.

\subsection{Barriers in the e-Government Services}

Information Technology is a major barrier in the implementation of the e-Government in Pakistan. The 92 per cent of the respondent completely agreed that no internet connection is the major reason creating an obstacle in implementing the eGovernment services in Pakistan. Also the remaining 08 per cent agreed with this being the major obstacle.

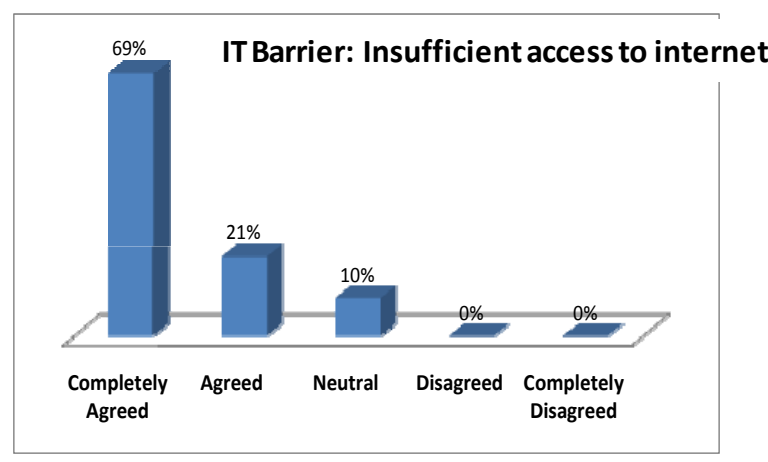

Figure 6. Insufficient access to Internet

The 69 per cent respondents agreed that insufficient computer system is the major reason creating an obstacle in implementing e-Government service in Pakistan. The 19 percent of the population completely agreed to this being the barrier for implementation of e-Government services.
A majority of respondents agreed to unavailability of websites as being the reason for creating an obstacle in implementation for e-Government services. Also there were respondents who also completely agreed to this being as the IT obstacle. The 59 per cent respondents agreed to low level of security for networks being as a barrier to smooth implementation of the e-Government in Pakistan and 28 respondents viewed it as being neutral services as far as barrier is concerned.

The 69 per cent respondents agreed that "shortage of literacy" is an obstacle for smooth eGovernment implementation in Pakistan. The 21 respondents are also completely agreed with this.

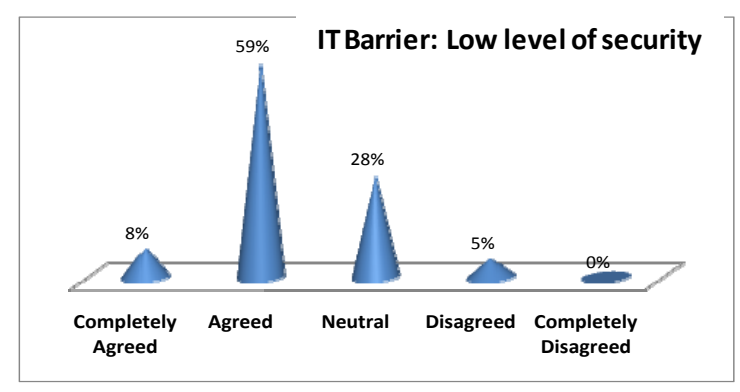

Figure 7. Low level of security for networks

The 57 per cent respondents agreed that lack of IT educational programme is creating a problem. Rest 14 respondents answered neutral and other 25 completely agreed to it with remaining 05 answering disagreed.

The 45 per cent respondents disagreed that low level of English language is creating a problem for implementation. Also 29 per cent are Neutral as to this being an obstacle. The 52 per cent respondents disagreed that low motivated IT workforce in the organization is creating a problem for implementation. The 25 respondents are Neutral as to this being an obstacle. Another 23 respondents only agreed to this. Out of the total 100 respondents, 67 respondents were Neutral that employees do not understand the advantages of the e-Government and 23 respondents agreed to it as to this being an obstacle. Another 09 respondents only disagreed to this.

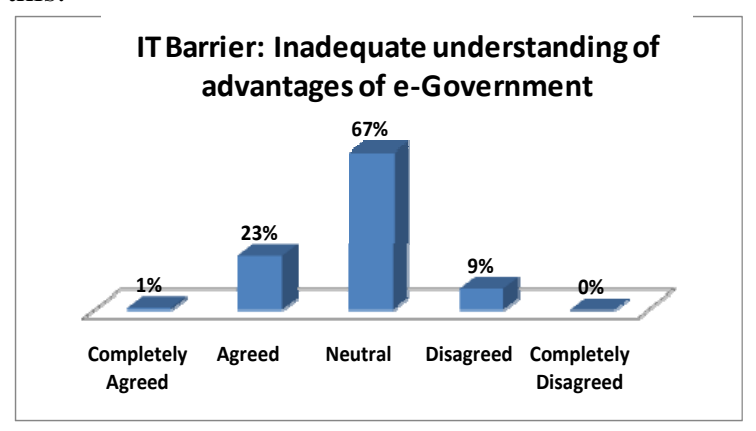

Figure 8. Inadequate understanding of advantages of eGovernment 
Majority of the people responded with Neutral with respect to lack of security policy and law. The 21 respondents stated that they agreed with "lack of security policy and law” being a barrier. The 60 per cent respondents are agreed that lack of strategic plan is a barrier towards smooth implementation of the e-Government in Pakistan. The 30 per cent respondents stated it as Neutral. By finding out about the legal barrier, lack of implementation of IT policy was agreed by more than 50 per cent of the respondents.

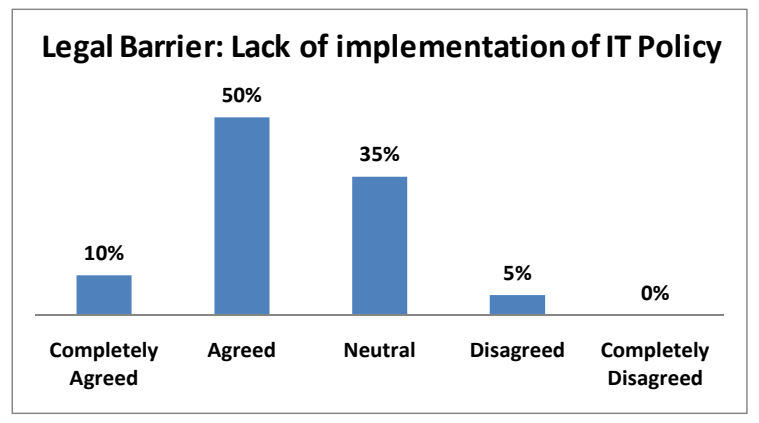

Figure 9. Lack of strategic plan

Non security feeling towards data in the eGovernment also hindered the smooth implementation of it and more than 50 per cent of the respondents completely agreed as it being an obstacle. In fact nearly 30 per cent respondents agreed to this being an obstacle.

\section{Conclusion and recommendations}

Based on the survey result, the research draws a conclusion which is showcasing the expectations of the kind of e-services required by the citizens of Pakistan. Pakistan is a developing nation and with increased commercialization there is an immediate need to increase its e-service platform to wider masses and classes. In a survey done by the United Nations, Pakistan comes in mid range as far as its eGovernment services are concerned. Overall the survey has resulted that out of the so many e-services listed in the questionnaire the most commonly used e-service by the citizens of Pakistan was education, job, utility bills, passport and taxation. It has also been observed that most of the citizens use Internet on a regularly basis which shows the increasing penetration of internet and computer services in Pakistan.

It is important that a proper and integrated eGovernment system should be developed to disseminate the correct form of information across its citizens.

- There is a need to increase the participation from the citizen's end so as to utilize maximum number of e-services. There should be information through electronic and print media about the existing programmes of Electronic Government Directorate to aware citizens about the advantages of eGovernment and how they can utilize those advantages.

- Government should move e-services from federal level to provincial and local council's level, because citizens of Pakistan are more concerned to utilize the

Government services at the lower level. There should be portal for every city or for every local council which is operating within the city, such as in United Kingdom every council has their own portal and citizen's can access any time.

- In Pakistan there is a need of political stability and administration reforms for the widespread of the e-Government programmes like trainings, management programmes and free supply of electricity. There should be special reforms such as increase in literacy rate and IT skills for those citizens who are living in rural areas and citizens should have full confidence on political structure and administration reforms.

- Government should appoint high caliber IT literate officials and a "One-Stop portal needs to be in place which integrates all the other pages, departments and agencies.

- Higher level of awareness is required so as to embrace e-Government services and government should launch free programmes for educating and training to increase IT skills among citizens.

- $\quad$ Flexibility need to be shown on its website so as to properly portray the culture and language in front of all its stakeholders. For example if a German businessman wants to find out about Pakistan as a business destination, it is required that information is published in German language as well.

\section{References}

[1] Jaeger, P. T. and Thompson, K.M. "E-Government Around the World: Lessons, Challenges and Future Directions" Government Information Quarterly, Vol. 20, No. 4, pp. 389394, 2003

[2] McLean, M. \& J, Tawfik, 'The role of Information and Communication Technology in the modernization of eGovernment', PP 237-245, 2003.

[3] Schware, R., \& Deane, A. Deploying e-Government programs: The strategic importance of me before E.Info, The journal of policy regulation and strategy for telecommunications, 5(4), 10 19. 2003.

[4] Huggins, Richard, "The nature of the state, in Barrie Axford, Gary Browning”. Richard Huggins et al, Politics: An introduction, London, Rutledge, p: 268-270, 1997. 
[5] Plano, Jack. and Olton Roy, The International Relations Dictionary,Fourth edition, Longman, 2000.

[6] Riley, T.B, E-Government vs. E-Governance: Examining the Difference in a Changing Public Sector Climate, The Commonwealth Secretariat and Government Telecommunications and Information Services, Public Works and Government Services, Ottawa, 2003.

[7] Bedi, K., Singh, P.J., Srivastava, S., Government@net: New Governance Opportunities for India, Sage Publications, New Delhi, 2001.

[8] Fraga, E, "Trends in e-Government: how to plan, design, and measure e-Government", paper presented at the Government Management Information Sciences (GMIS) Conference, Santa Fe, NM, June 2002,

[9] Audit Office of New South Wales (2001), E-Government: Use of the Internet and Related Technologies to Improve Public Sector Performance, Audit Office of New South Wales, Sydney, Performance Audit Report, 2001

[10] Barzilai-Nahon, K. Gaps And Bits: Conceptualizing Measurements For Digital Divide/s . In The Information Society, 10 de junio de 2003, 22(5), 269-278, 2006.

[11] Ciborra, C., Interpreting e-Government and Developing Efficiency, Transparency or Governance at a Distance? Information Technology and People, Vol. 18, No.3, pp. 260279, 2005 